
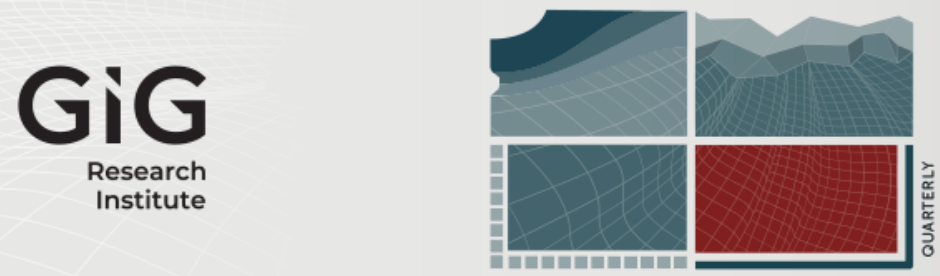

JOURNAL

OF

SUSTAINABLE

MINING

Volume 19 | Issue 3

Article 6

2020

\title{
New research on a case of Linear Discontinuous Ground Deformation (LDGD)
}

Author(s) ORCID Identifier:

Andrzej Kowalski (iD 0000-0002-1218-8528

Bartosz Apanowicz (iD) 0000-0002-7268-8786

Piotr Polanin (iD) 0000-0002-8184-4170

Follow this and additional works at: https://jsm.gig.eu/journal-of-sustainable-mining

Part of the Environmental Monitoring Commons, Geology Commons, and the Tectonics and Structure Commons

\section{Recommended Citation}

Kowalski, Andrzej; Apanowicz, Bartosz; and Polanin, Piotr (2020) "New research on a case of Linear Discontinuous Ground Deformation (LDGD)," Journal of Sustainable Mining: Vol. 19 : Iss. 3 , Article 6. Available at: https://doi.org/10.46873/2300-3960.1018

This Research Article is brought to you for free and open access by Journal of Sustainable Mining. It has been accepted for inclusion in Journal of Sustainable Mining by an authorized editor of Journal of Sustainable Mining. 


\title{
New research on a case of Linear Discontinuous Ground Deformation (LDGD)
}

\begin{abstract}
LSDS is defined as surface fissures, steps as well as structures formed by them in the form of stairs (several steps), thresholds, ditches, and flexure. The paper presents a case study of formed LSDS - the origin, and possible methods to assess its occurrence on the basis of the research carried out in the Central Mining Institute. The authors showed that the presence of LSDS leads not only to the horizontal deformation but also contributes to the formation of vertical curvatures of terrain that cause fissures in the near-surface layer of the rock mass in the areas with a thick layer of tertiary clay and a thin layer of Quaternary strata. The accumulated experience also indicates that there is an influence of other mining factors, such as the interval between operations, rate, and direction of operation, which may contribute to the occurrence of LSDS. Moreover, the authors pointed to the fact that forecasting LSDS is problematic and complex and is subject to uncertainty. At the same time, the scoring method is quite effective in the case of LSDS forecasting.
\end{abstract}

\section{Keywords}

underground mining, linear discontinuous surface deformation, case study

Creative Commons License

(c) (i)

This work is licensed under a Creative Commons Attribution 4.0 License. 


\title{
New research on a case of Linear Discontinuous Ground Deformation (LDGD)
}

\author{
Andrzej Kowalski, Bartosz Apanowicz*, Piotr Polanin
}

Central Mining Institute, Plac Gwarków 1, 40-166 Katowice, Poland

\begin{abstract}
LDGD is defined as surface fissures, steps as well as structures formed by them in the form of several steps, thresholds, ditches, and flexure. The paper presents a case study of formed LDGD - the origin, and possible methods to assess its occurrence on the basis of the research carried out in the Central Mining Institute (Poland). The authors showed that the presence of LDGD leads not only to the horizontal strain but also contributes to the formation of vertical curvatures of terrain that cause fissures in the near-surface layer of the rock mass in the areas with a thick layer of tertiary claystones and a thin layer of Quaternary strata. The accumulated experience also indicates that there is an influence of other mining factors, such as the interval between operations, face advance, and direction of operation, which may contribute to the occurrence of LDGD. Moreover, the authors pointed to the fact that predicting of LDGD is problematic and complex and is subject to uncertainty. The authors showed that both of LDGD methods prediction, when first of them is based on horizontal strains index and second one is points method, have good verifiability in practice.
\end{abstract}

Keywords: underground mining, linear discontinuous ground deformation, case study

\section{Introduction}

$\mathrm{T}$ he state of knowledge on ground deformation of mining areas is largely based on the research and analysis of recorded cases. Thus, the area of linear discontinuous ground deformation (LDGD) is solely based on experience and lacks a theoretical basis. Each new case of LDGD is an opportunity to study this phenomenon.

LDGD, also referred to as linear discontinuities or linear deformations, is defined as surface fissures, steps as well as structures formed by them in the form of several steps, thresholds, ditches, and flexure [1]. The cases are usually recorded when they are visible to the naked eye; in practice, however, they are recorded when the fissures are at least $0.01 \mathrm{~m}$ wide and more than $0.05 \mathrm{~m}$ high. They are usually found on roads, squares, in built-up areas and less often in agricultural areas.

Although underground exploitation in Poland in the XXI century is already taking place at medium and large depths, the occurrence of LDGD is still visible. The cases are analysed and described.

The objective of the paper is to present the recorded cases of LDGD, the origin and to interpret the mechanisms of the occurrence. This is a case study, based on the experience of a mine in the south-western part of the Upper Silesian Coal Basin in Poland.

\section{State of knowledge}

The occurrence of the LDGD was described in papers on mining deformations [2,3]. The widest range of studies covering the analysis of 1138 discontinuities in the Ruhr area on the western bank of the Rhine was carried out by Grün [4]. Based on the collected research results, he elaborated a predicting matrix, in which he methodically combined geological and mining data with data on LDGD. The result of the prediction depends on qualitative and quantitative estimates of mining impacts affecting the probability of occurrence or activation of discontinuities. The method makes it possible to

Received 17 August 2020; revised 12 November 2020; accepted 12 November 2020.

Available online 05 December 2020

* Corresponding author.

E-mail address: bapanowicz@gig.eu (B. Apanowicz). 
predict potential "routes of origin" of discontinuities and their qualitative structure. There is also a distinction between the occurrence of new LDGD and the reactivation of the existing ones (secondary ground deformation). The qualitative and quantitative results of the analyses are mutually evaluated using a scoring system.

In recent years, there have also been reports of LDGD in Chinese hard coal mining, with two types of fissures in mountainous areas: slide-type on the slopes, and step-type in valleys [5]. The relationship between the LDGD fissure width and the horizontal strain value was also shown (Fig. 1).

The graph from Fig. 1 partially confirms the Polish results of tests of horizontal loosening of soil samples from which it results that the ranking status (formation of vertical fissures) may occur in case of non-cohesive soils for horizontal strains in the range of $2-4 \mathrm{~mm} / \mathrm{m}$ and for cohesive soils in the range of 3-9 $\mathrm{mm} / \mathrm{m}$ [6]. On the other hand, the widths of the fissures are much smaller in the conditions of Polish mines.

In Poland, descriptions of the formation of fissures and steps on ground caused by underground exploitation of coal seams at depths of about $300 \mathrm{~m}$ were presented by Klenczar [7], and also much later (on one of the mines) in articles published by the Silesian University of Technology (Poland) [8].

In the years from 2006 to 2009, in the Central Mining Institute in Poland, within the framework of the research project, about 400 LDGD were catalogued (including the type, geometric data, geological-mining conditions in which they occurred) $[1,9]$. These studies have resulted in the development of two methods for determining the risk of occurrence of LDGD, inspired by Grün's research.

It can be concluded that two deterministic predicting method for LDGD has been formulated so far in Central Mining Institute:

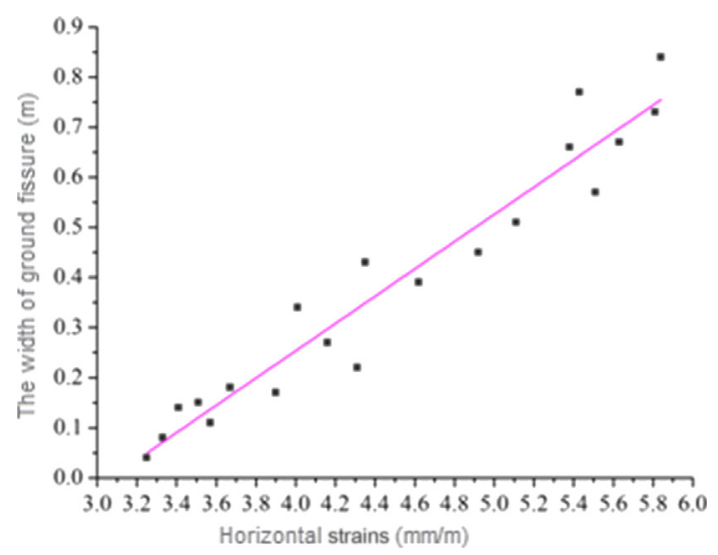

Fig. 1. The relationship between the ground fissure width and the horizontal strain value [5].
- First one based on the predicted (calculated) values of horizontal strains induced by performed and planned mining exploitation where horizontal strain is a synthetic indicator affecting the occurrence of LDGD.

- Second one (point method) based on four components: the previous and predicted horizontal strains, geological structure and face advance.

The timing of LDGD occurrence cannot be predicted. In the point method the conditions (probability) of their occurrence are strongly influenced by geological and mining conditions during mining operations, in addition to horizontal tensile strains. They are different for every type of exploitation. Therefore, research results should not be uncritically transferred from one mining area to another.

\section{New research}

\subsection{Description of LDGD}

Figs. 2 and 3 show LDGD, which had the form of steps up to $0.3 \mathrm{~m}$ high and fissures up to $0.2 \mathrm{~m}$ wide (photo 1, 2 and 3). They created a zone composed of several, usually up to five degrees, creating ditches (photo 4) and flexures (photo 5). The width of the zone was $80-90 \mathrm{~m}$ and occurred between 20 and $110 \mathrm{~m}$ from the operating edge of the seam $404 / 5$ (green colour in Fig. 2).

The formation of the original LDGD is linked to the exploitation of seams 404/3 and mainly 404/5 which occurred during March and April 2018 after the end of exploitation longwall S/z II-II in 404/5 seam (Table 1).

Exploitation of the third seam (405/1) by longwall S/z I-II in 2019, resulted only in a slight increase of steps and reactivation of some LDGD occurred in 2018. It was so called secondary occurrence of LDGD in 2019.

\subsection{Geological and mining conditions}

Fig. 3 shows the LDGD, contours of the exploited seams, and Fig. 4 shows a schematic horizontal view of tectonic faults outcrops in the roof of Carboniferous hard coal seam's layers.

Quaternary, tertiary, and Carboniferous formations form part of the geological structure of the rock mass. Directly to the north of the exploitation, there is a Fault II zone with the direction north-east south-west with the drop height of between 200 and $230 \mathrm{~m}$ in the north-west direction (Fig. 4). The 


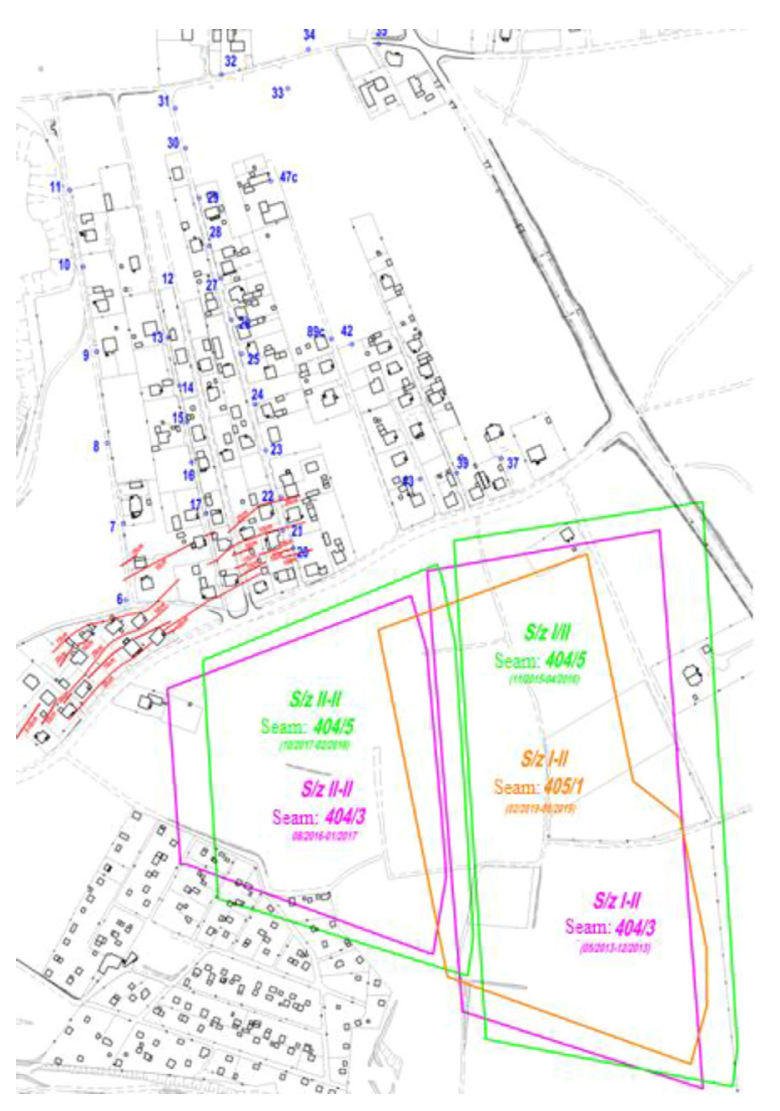

Fig. 2. Map with the buildings, LDGD, measuring points and outline of the operating seams 404/3 (purple), 404/5 (green) and 405/1 (brown).

thickness of the younger layers (above the Carboniferous) is about $200 \mathrm{~m}$ on the southern side and about $250 \mathrm{~m}$ on the northern side of Fault II. They are built of a thin quaternary layer and a thick tertiary layer. The quaternary layers, about $10 \mathrm{~m}$ thick, form alternating layers of clay, sandy clay, gravel, and sand. The tertiary layers, about $200 \mathrm{~m}$ thick, are made of clay and marl.

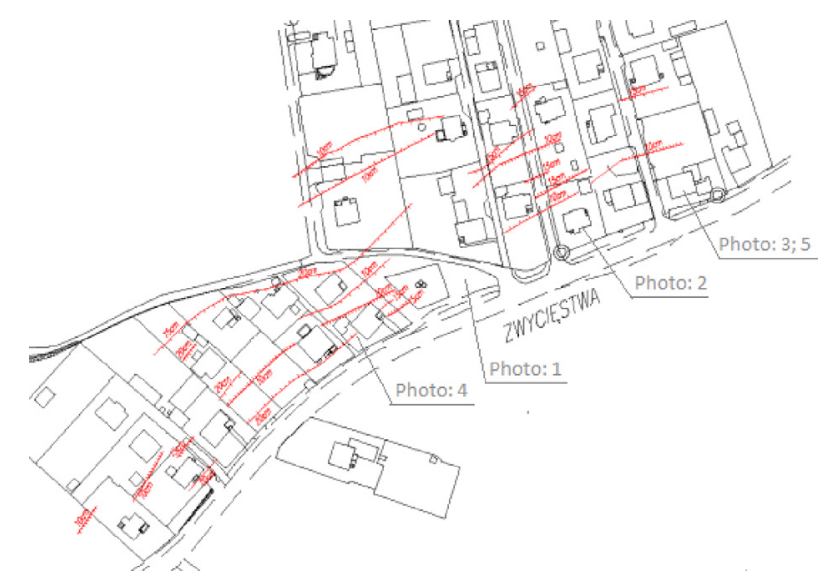

Fig. 3. Sketch of the LDGD with the heights of the steps and the structures made up of them.
The Carboniferous formations are represented by the Orzesze and Ruda layers and the saddle layers below. The Orzesze layers, about $340 \mathrm{~m}$ thick, and directly beneath them, there are Ruda layers about $670 \mathrm{~m}$ thick.

The geological and mining data of the mining operations to the south of the Fault II zone which caused LDGD are presented in Table 1. It should be noted that at the same time the exploitation north and northeast of the fault zone was carried out, which was not significant effect on the formation of LDGD.

Table 1 shows that the eastern longwalls S/z I-II in seams $404 / 3$ and $404 / 5$ were exploited first and then western longwalls S/z II-II. The time interval between S/z I-II longwalls in seams 404/3 and 404/5 was 2.5 years, and between S/z II-II longwalls - one year and three months. Then a thin seam 405/1 with a single S/z I-II longwall was exploited at an interval about 1.5 years long. The operations were conducted in the direction from north to south.

\subsection{Results of geodetic measurements of subsidence}

On the surface in the area of the building development, there was a network of ground measurement points, which form short measurement lines along the streets north of Zwycięstwa Street (Figs. 2 and 5), on which since 2011 the measurements of subsidence are made. Fig. 5 shows the contours of subsidence caused by exploitation in seams $404 / 3$ and 404/5, and Fig. 6 shows the profile of subsidence on the selected line in north-south direction as well as determined parameters of the Knothe-Budryk theory with exploitation edge.

The Knothe-Budryk theory is a geometric - integral theory which was formulated on an empirical basis. The influence function was applied as

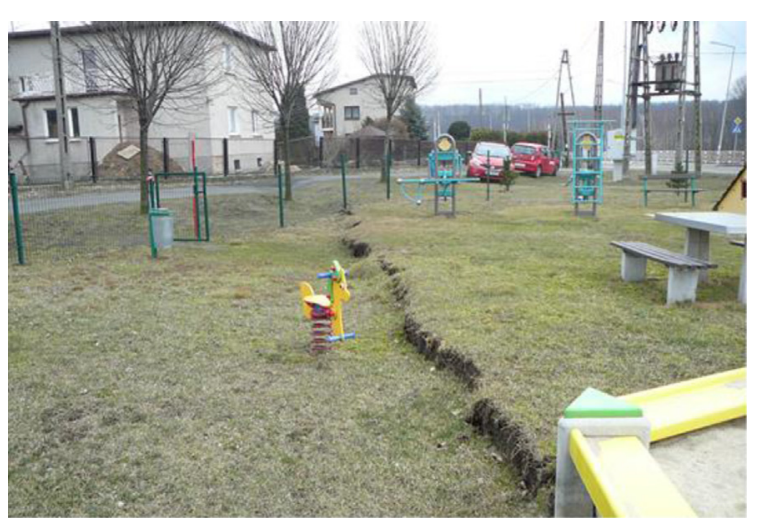

Photo 1. LDGD in the form of a step $0.3 \mathrm{~m}$ high. 


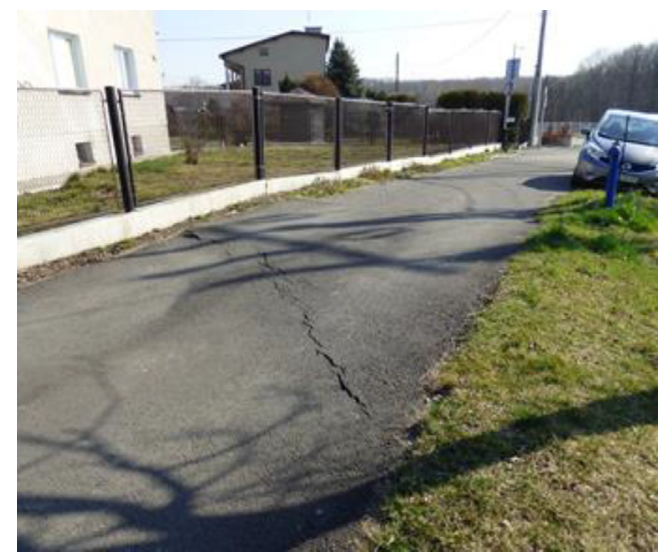

Photo 2. LDGD in the form of steps and fissures $0.05 \mathrm{~m}$ wide.

Gaussian normal distribution. The basic parameters are:

- operation factor (a) - it characterizes a method of roof control (for instance caving),

- rock mass parameter $(\operatorname{tg} \beta)$ - it describe the properties of the rock mass,

- operating edge - it is an additional parameter, which describes the deflection of the main roof and the shift of subsidence trough profile towards the goaf.

The Knothe-Budryk theory is commonly used in Polish underground mining to describe and predict subsidence.

Figs. 5 and 6 show that the exploitation of two seams with four longwalls resulted in subsidence was between $0.45 \mathrm{~m}$ and $1.15 \mathrm{~m}$ in the LDGD area. The inclination over a short section (20-21) $20 \mathrm{~m}$

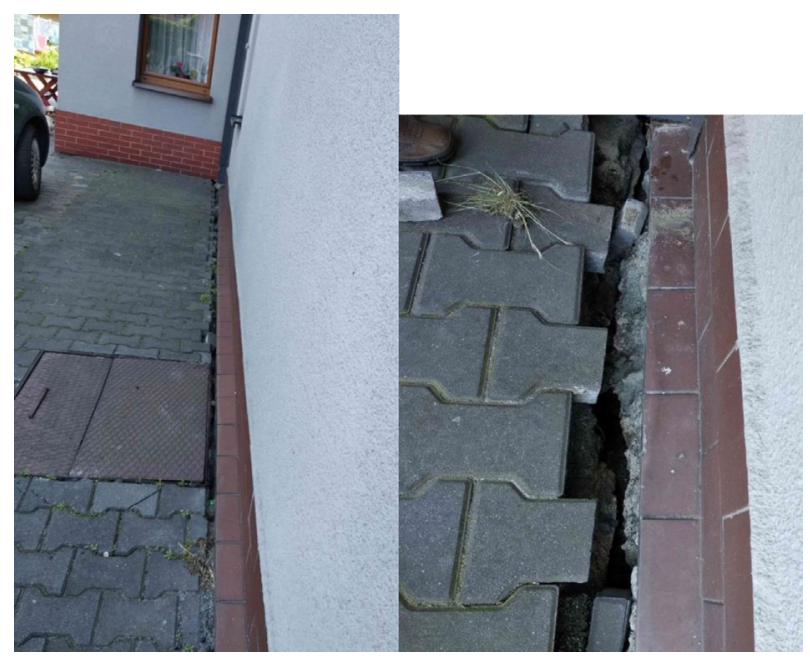

Photo 3. . LDGD in the form of a fissure $0.07 \mathrm{~m}$ wide; general view (left), close-up (right).

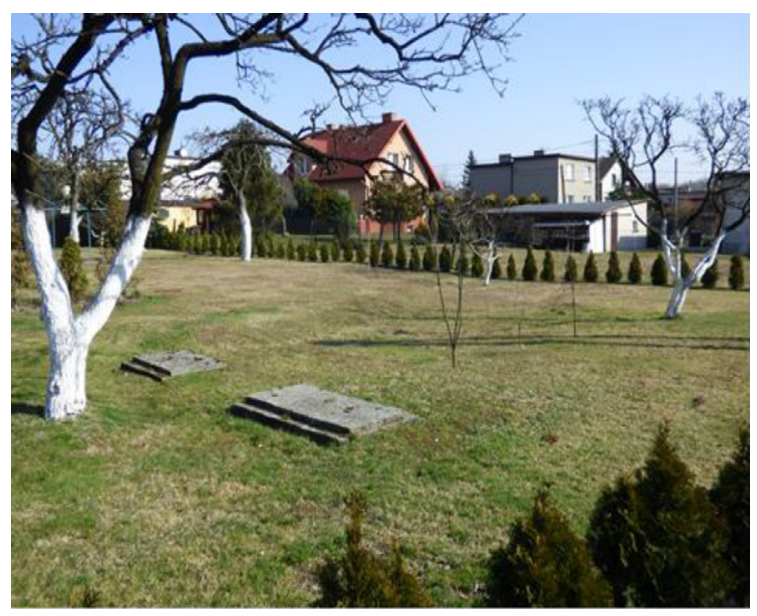

Photo 4. . LDGD in the form of a typical ditch.

long was $28 \mathrm{~mm}$. Assuming an average length of the section $(20-22)$ to be $50 \mathrm{~m}$, the inclination will reach $14 \mathrm{~mm} / \mathrm{m}$. The radius of curvature derived from the three measurement points (20-21-22) is less than $1.0 \mathrm{~km}$. These are large values of deformation indicators corresponding to category IV and V of the mining area.

Measurements of subsidence in the analysed case are unfavourable for determining the parameters of the Knothe - Budryk theory, due to the location of measurement points, as well as the impact of exploitation carried out north-east of the northern part of the measurement lines and analysed area.

\subsection{Theoretically calculated horizontal strains}

The values of determined parameters of the theory are.

- operation factor $\mathbf{a}=0.7$,

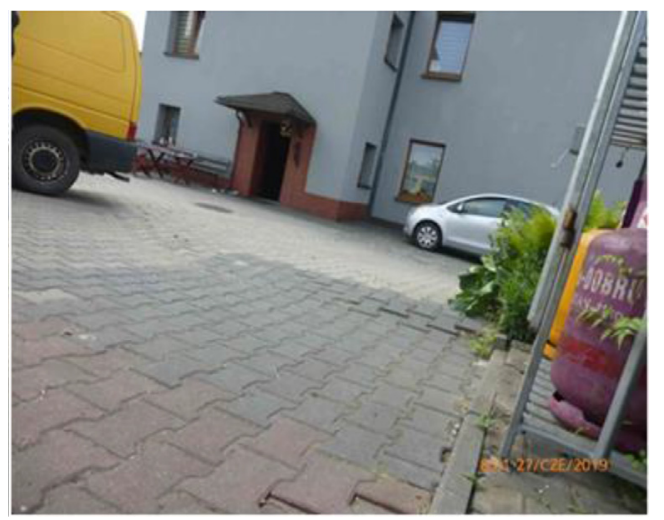

Photo 5. . LDGD in the form of flexure. 
Table 1. Completed mining operation to the south of the buildings.

\begin{tabular}{|c|c|c|c|c|c|c|c|c|}
\hline Longwall & Seam & $\begin{array}{l}\text { Mean height of } \\
\text { seam }[\mathrm{m}]\end{array}$ & $\begin{array}{l}\text { Mean depth of } \\
\text { exploitation }[\mathrm{m}]\end{array}$ & Start date & Finish date & $\begin{array}{l}\text { Seam slope } \\
{\left[{ }^{\circ}\right]}\end{array}$ & $\begin{array}{l}\text { Azimuth of seam } \\
\text { slope }\left[{ }^{\circ}\right]\end{array}$ & Roof control \\
\hline $\mathrm{S} / \mathrm{z} \mathrm{I}-\mathrm{II}$ & $404 / 3$ & 4.20 & 445 & 04.2013 & 01.2014 & 19 & 176 & caving \\
\hline S/z II-II & $404 / 3$ & 3.55 & 552 & 07.2016 & 03.2017 & 18 & 180 & caving \\
\hline S/z I-II & $404 / 5$ & 3.24 & 457 & 11.2015 & 04.2016 & 18 & 175 & caving \\
\hline S/z II-II & $404 / 5$ & 3.50 & 535 & 10.2017 & 02.2018 & 19 & 176 & caving \\
\hline S/z I-II & $405 / 1$ & 2.3 & 543 & 02.2019 & 08.2019 & 20 & 185 & caving \\
\hline
\end{tabular}

- rockmass parameter $\operatorname{tg} \beta=1.5$,

- operating edge $p=90 \mathrm{~m}$,

- Deviation factor due to the slope of the coal seams $k=1.2$.

Fig. 7 and Fig. 8 show respectively the subsidence and the tensile strains horizontal strains caused by exploitation of seams $404 / 3$ and 404/5 which were calculated based on determined parameters of Knothe-Budryk theory.

Back calculations show that the operation of seams $404 / 3$ and 404/5 has resulted in subsidence of up to $1.2 \mathrm{~m}$ in the area of the zone where LDGD occurred (Fig. 7), and horizontal tensile strains could have value up to $+8.0 \mathrm{~mm} / \mathrm{m}$.

\section{Discussion of LDGD predicting methods}

\subsection{Factors affecting the formation of LDGD}

The formation of LDGD in the analysed example has its origins in the unfavourable summation of horizontal tensile strains caused by the exploitation of thick seams $404 / 3$ and 404/5. The values of calculated horizontal strains close to the index corresponding to the IV and $\mathrm{V}$ category of mining areas $(+9.0 \mathrm{~mm} / \mathrm{m})$. It is a verification of the predicting method based on horizontal strains (Fig. 9).

The additional circumstances contributing to the formation of LDGD are the geological structure of the rock mass, the occurrence of the fault zone II, having outcrops in the Carboniferous roof directly south of this zone, and a thick layer of tertiary formations mainly of claystones.

The operation of S/z II-II longwalls in seams 404/ 3 and 404/5 was carried out at a short interval of 1 year and 3 months in a block system. The impact of the so-called starting edges of longwalls cannot be excluded, as well as the impact of the longwall face advance on the occurrence of the LDGD, which averaged value was equal to $3.3 \mathrm{~m} /$ day. In conclusion the impact of geological and mining factors is significant.

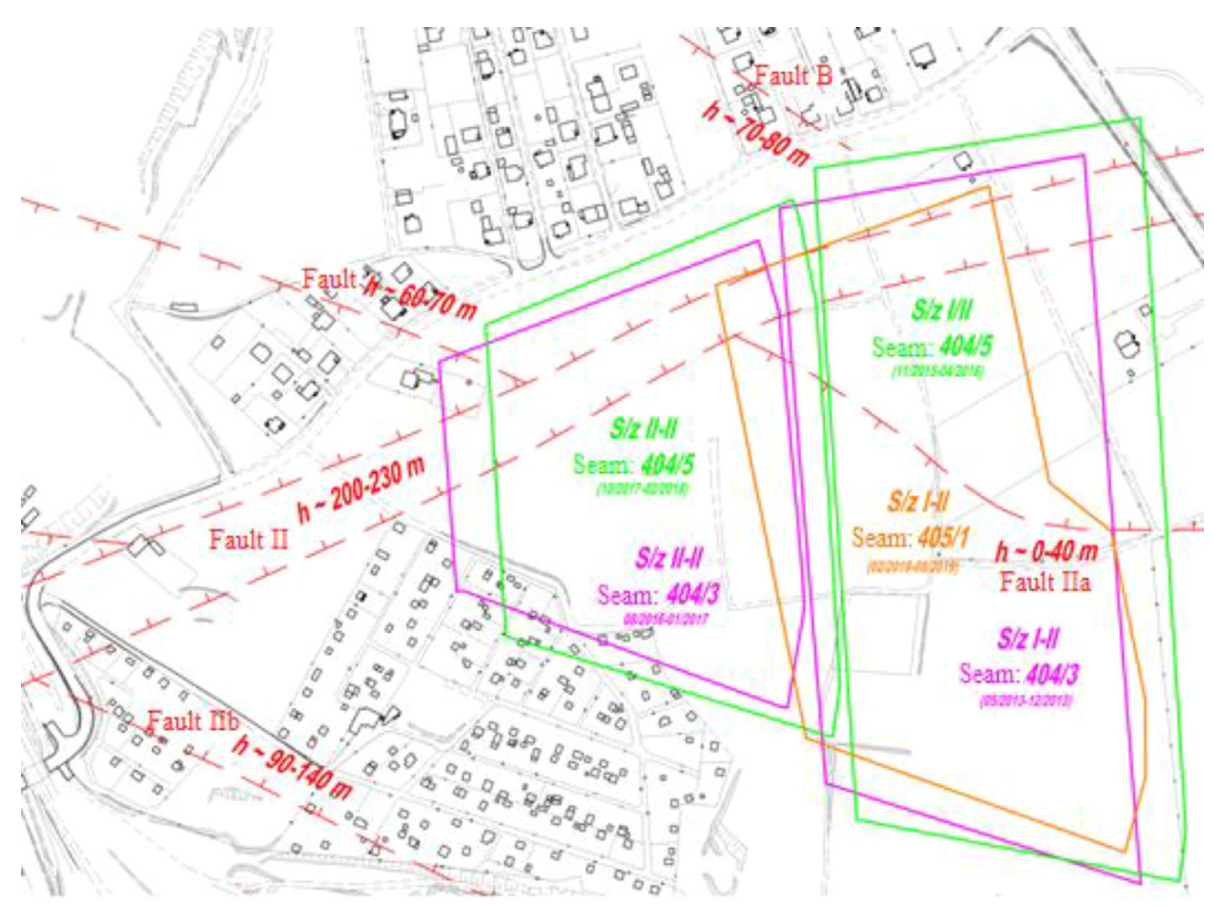

Fig. 4. Outcrops of tectonic faults in the Carboniferous roof, LDGD zone and mining operations carried out in seams 404/3 and 404/5. 


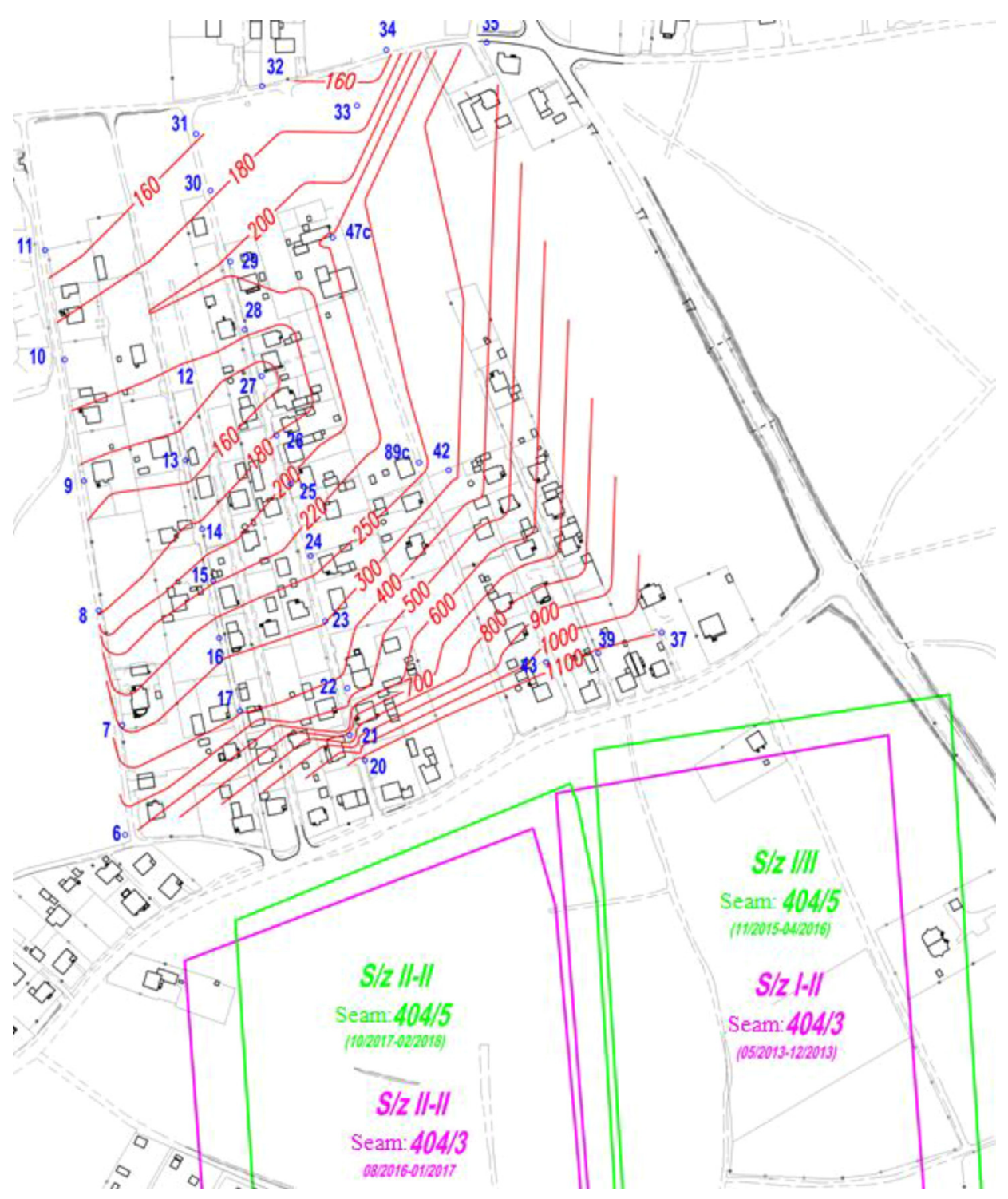

Fig. 5. Contours of subsidence caused by exploitation of seams 404/3 and 404/5 between February 2011 and June 2018.

The above statement predisposes the point method for prediction of LDGD.

\subsection{New experience in the light of current research}

From the research conducted in Central Mining Institute [1, 9], an empirical dependence of the probability of occurrence of primary (initial) LDGD was determined on total values of horizontal strains caused by the exploitation of several seams, which is shown in Fig. 9. The adjusted coefficient of determination was $R^{2}=0.6984$, which was considered satisfactory for empirical data from many mines. In the analysed example, the probability of LDGD for horizontal strains of $8.0 \mathrm{~mm} / \mathrm{m}$ is about $40 \%$, which is very low (Fig. 9). This raises the question about the range of LDGD in analysed example.

The answer to this question can be given based on several factors:

- Geological structure of the rock mass, occurrence of a thick layer of tertiary claystone and a thin layer of quaternary, which bent (convex curvature) in the area of occurrence of the LDGD where horizontal strains (up to $9.0 \mathrm{~mm} /$ $\mathrm{m})$, and vertical curvature (about $1 \mathrm{~km}$ ) were occurred. In the near-surface layer, the rock mass has been vertically fissured.

- Second-order causes (geological and mining factors), the influence of face advance (an average of $3.3 \mathrm{~m} /$ day) and two starting 


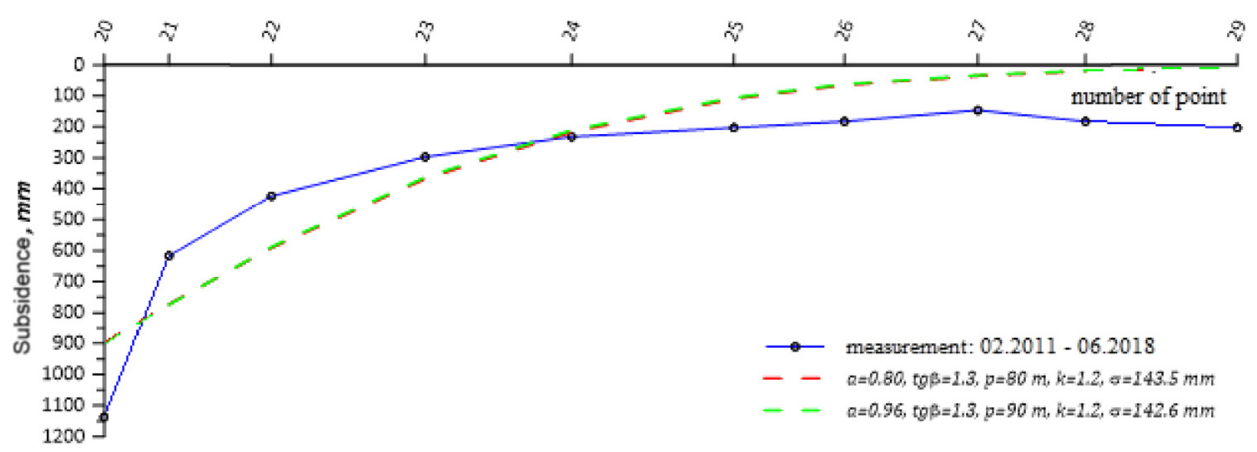

Fig. 6. Results of the adjustment of parameters of the Knothe-Budryk theory with the operational edge between February 2011 and June 2018, along the defined line 2.

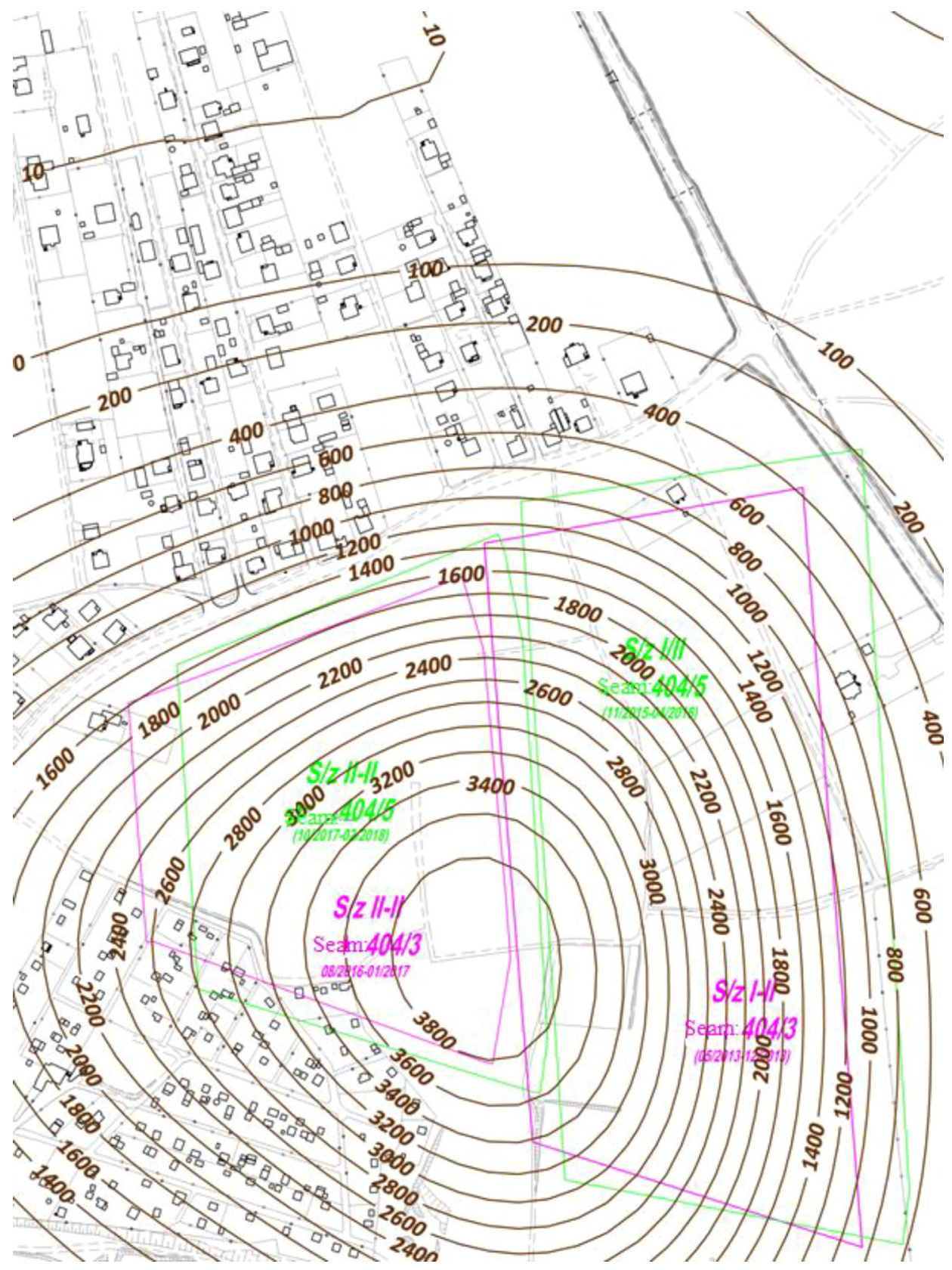

Fig. 7. Calculated subsidence due to exploitation of seams $404 / 3$ and 404/5. 


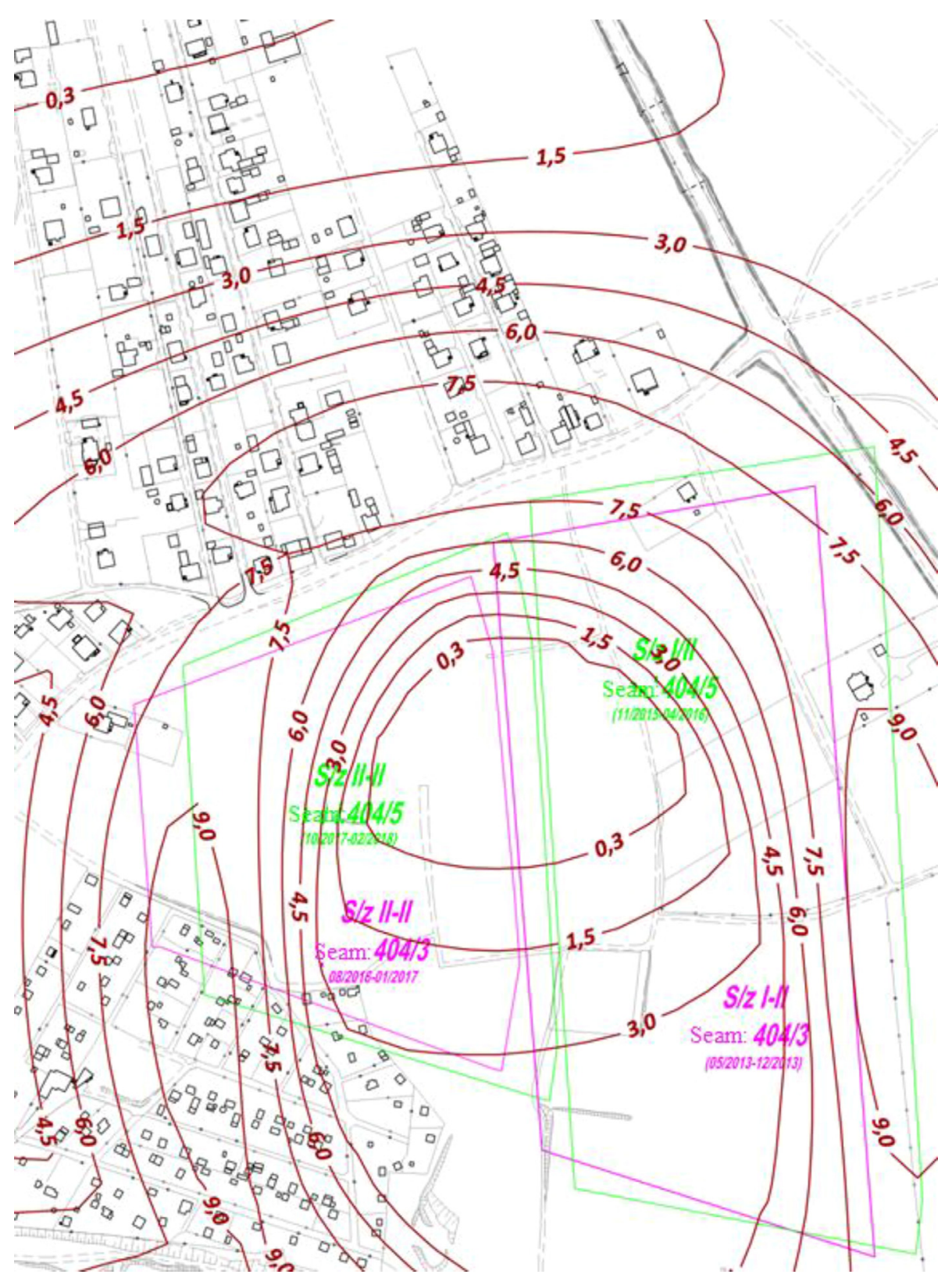

Fig. 8. Calculated tensile horizontal strains due to exploitation of seams 404/3 and 404/5.

longwalls edges, and mainly the short interval between the start of S/z II-II longwalls and their operation in a block system could be equally relevant.

The occurrence of secondary LDGD caused by next exploitation (third seam 405/1 with a thickness of up to $2.3 \mathrm{~m}$ with a single longwall at an interval of 1 year and 3 month) did not result in a significant increase of LDGD, but only the reactivation of one discontinuity. The calculated increase of horizontal tensile strains due to operation of seam 405/1 did not exceed $3.0 \mathrm{~mm} / \mathrm{m}$ (Fig. 10). This case example corresponds very well to the usage of the strain method for prediction of secondary LDGD (Fig. 11) According to the previous research of Central Mining Institute during 2006-2009, the determined coefficient of matching was $R^{2}=0.9974$ for the occurrence of secondary LDGD [1].

The graph in Fig. 11 shows that in the area where LDGD occurred their activation may occur with very small deformations (II category of mining area $1.5 \mathrm{~mm} / \mathrm{m}<\epsilon<3.0 \mathrm{~mm} / \mathrm{m}$ ), while its increase is significant for horizontal strains which values are 


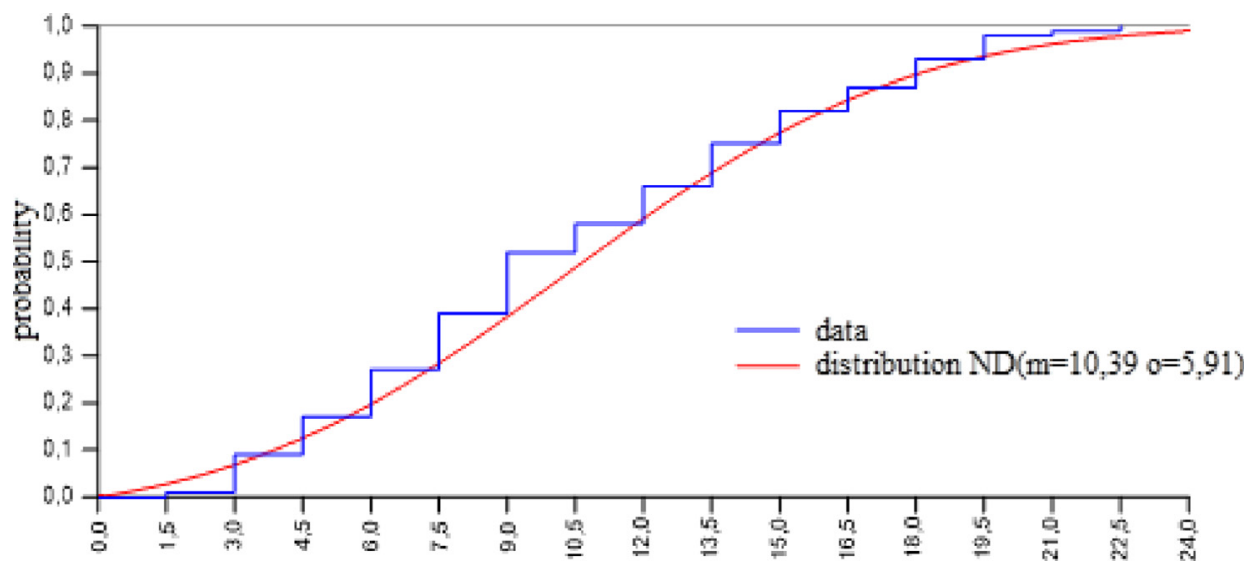

Fig. 9. Probability of occurrence of primary discontinuity for horizontal tensile strain [1].

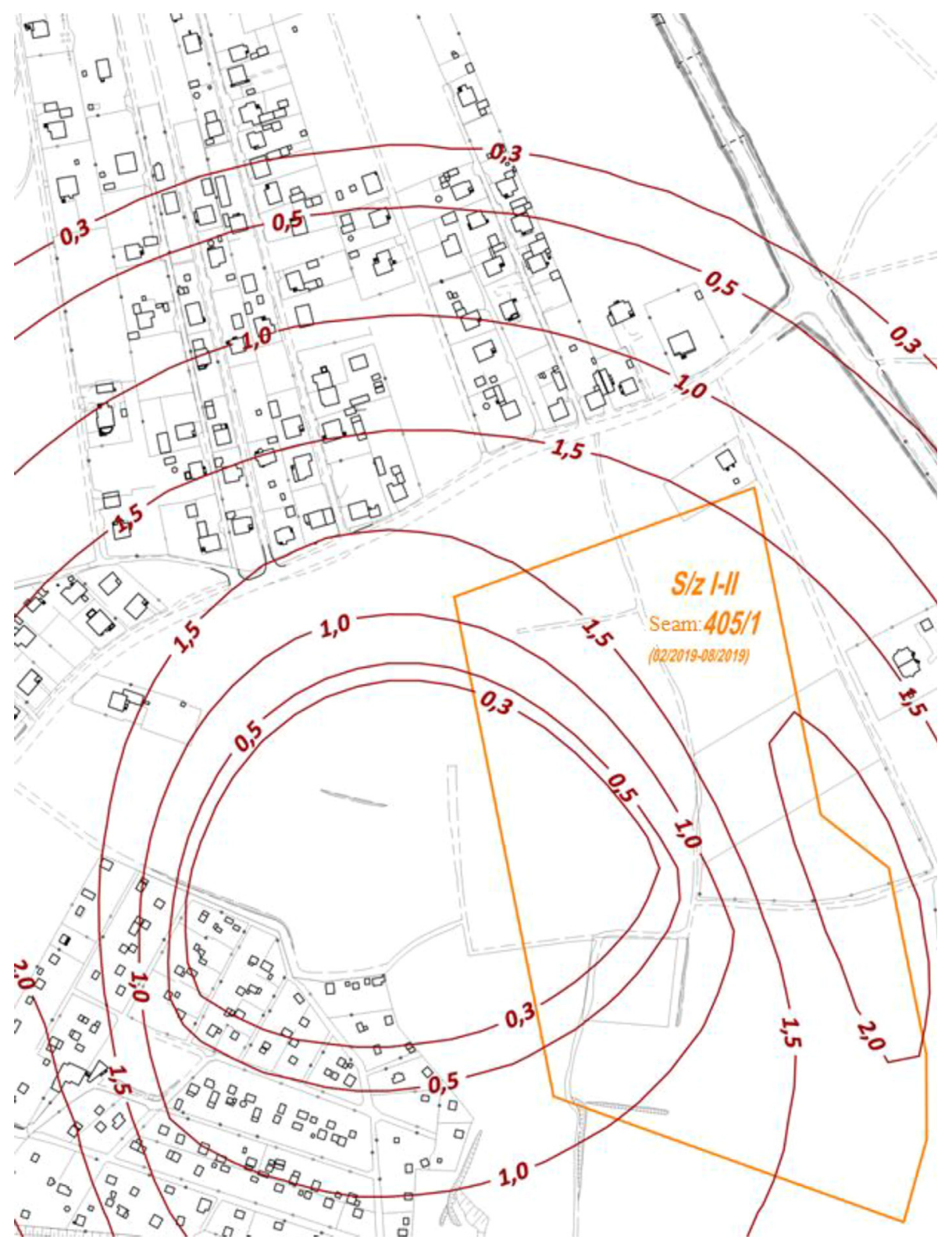

Fig. 10. Calculated horizontal tensile strains due to exploitation of seam 405/1. 


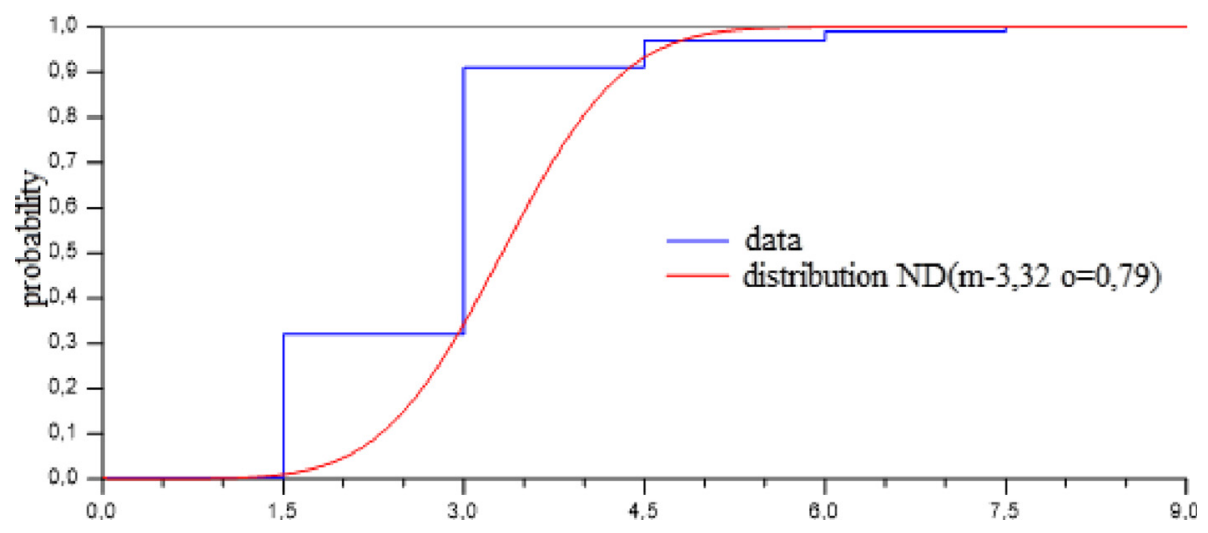

Fig. 11. The probability of occurrence of secondary discontinuity at horizontal strain $E_{\text {sum }}$ [1].

higher than $3.0 \mathrm{~mm} / \mathrm{m}$, which corresponds to III category of mining area.

\subsection{Advantages and disadvantages of the proposed methods}

The methods developed by Central Mining Institute are not faultless but it can be useful, what was presented in the article. It is the first method in Poland for predicting LDGD, which is based on the basic indicator responsible for ground deformation (horizontal strain). Both methods were developed on the basis of the analysis of 343 cases of LDGD, the calculated horizontal strains and the geological and mining factors which they occurred.

The disadvantage of these methods is the determination of horizontal strains in long periods of time, frequency of exploitation and time intervals between operations. In a longer period of time (more than two years), significant meaning has summing up the deformation (rheological properties) which are determined in approximately way or are not include at all for calculating the deformation of the rock mass. Despite of calculated deformation, geological conditions and velocity of exploitation are discretionary in the point method. Both methods are still tested.

\section{Conclusion}

1. The LDGD predicting methods were verified on the analysed new experience as practice example. These methods are not faultless but can be useful.

2. The demonstrated example shows that LDGD prediction is a complex problem and it is subject of high uncertainty, although it can be assumed that point method has better verifiability in practise. Point method despite of horizontal strains includes also geological and mining conditions to find out the reason of LDGD occurrence.

3. Further collecting and analysing the cases of LDGD occurrence is advisable to improve predicting methods proposed in this article. The research is also undertaken to detect LDGD with usage of satellite interferometry.

4. The gained experience also indicates the significant impact of the time interval between successive operations, face advance and direction of exploitation, which contribute to the occurrence of LDGD.

\section{Conflicts of interest}

None declared.

\section{Ethical statement}

The authors state that the research was conducted according to ethical standards.

\section{Funding body}

This research was funded by Polish Ministry of Science and Higher Education, Statutory Activity of the Central Mining Institute in Katowice no. $11342020-131$.

\section{References}

[1] Kowalski A. Deformacje powierzchni na terenach górniczych kopalń węgla kamiennego (Surface deformation in the mining areas of coal mines). Wydawnictwo Głównego Instytutu Górnictwa. Katowice; 2020.

[2] Whittaker DN. Reddish D.J. Subsidence. Occurrence, Prediction and Control. Amsterdam - Oxford - New York Tokyo: Elsevier; 1989.

[3] Kratzsch H. Bergschädenkunde. DeutscherMarkscheiderVerein e. v. Bochum; 1997. 
[4] Grün E. Analyse und Prognose von Unsteitigkeiten als Folge bergbaubedingter Bodenbewegungen im linksniederrheinischen Steinkohlengebiet. Dissertation. RWTH Aachen; 1995.

[5] Zhu H, He F, Zhang S, Yang Z. An integrated treatment technology for ground fissures of shallow coal seam mining in the mountainous area of south western China a typical case study. Mineral Resources Management 2018;34(1):119-38.

[6] Kwiatek J. Obiekty budowlane na terenach górniczych (The building objects in mining areas). Wydawnictwo Głównego Instytutu Górnictwa. Katowice; 2007.
[7] Klenczar T. Szkody górnicze (Mining damages). Stowarzyszenia Mierniczych Górniczych R. P. Katowice; 1939.

[8] Strzałkowski P, Piwowarczyk J, Łapajski K. Występowanie deformacji nieciagłych liniowych w świetle analiz warunków geologiczno - górniczych (Occurrence of discontinuous linear deformations in light of geological and mining conditions analyses). Przegląd Górniczy. 2006;6(5):1-5.

[9] Kowalski A, Jędrzejec E, Gruchlik P. Linear discontinuous deformations of the surface in the Upper Silesian Coal Basin. Archives of Mining Sciences 2010;55(2):331-46. 